\title{
Performance review and reengineering of the protection diodes of the LHC main superconducting magnets
}

\author{
F. Savary, M. Bajko, M. J. Bednarek, K. Dahlerup-Petersen, G. D'Angelo, G. Dib, C. Giloux, L. Grand-Clement, \\ S. Izquierdo Bermudez, R. Moron-Ballester, H. Prin, V. Roger, A. Verweij, G. Willering
}

\begin{abstract}
The LHC main superconducting circuits are composed of up to 154 series-connected dipole magnets and 51 series-connected quadrupole magnets. These magnets operate at $1.9 \mathrm{~K}$ in superfluid helium at a nominal current of $11.85 \mathrm{kA}$. Cold diodes are connected in parallel to each magnet in order to bypass the current in case of a quench in the magnet while ramping down the current in the entire circuit. Both the diodes and the diode leads should therefore be capable of conducting this exponentially decaying current with time constants of up to $100 \mathrm{~s}$. The diode stacks consist of the diodes and their heat sinks, and are essential elements of the protection system from which extremely high reliability is expected. The electrical resistance of 24 diode leads was measured in the LHC machine during operation. Unexpectedly high resistances of the order of $40 \mu \Omega$ were measured at a few locations, which triggered a comprehensive review of the diode behaviour and of the associated current leads and bolted contacts.

In this paper the thermal and mechanical analysis of the critical parts and bolted contacts is presented, and the results are discussed. Due to a lack of mechanical rigidity and stability, the bolted contacts between the diode leads and the busses of the quadrupole magnets have been redesigned. The consolidated design is described, as well as the dedicated tests carried out for its validation prior to implementation during the long shut down of the LHC machine that is scheduled between March 2013 and December 2014.
\end{abstract}

Index Terms-Bypass diode, Diode stack, Bolted contacts, Superconducting magnets.

\section{INTRODUCTION}

$T$ HE LHC main superconducting magnets operate at $1.9 \mathrm{~K}$ in superfluid helium at a nominal current of $11.85 \mathrm{kA}$. The main superconducting circuits are composed of up to 154 series-connected dipole magnets and 51 series-connected quadrupole magnets. Cold diodes operating at $1.9 \mathrm{~K}$ are connected in parallel to each magnet in order to bypass the current in case of a quench in the magnet while ramping down the current in the entire circuit. The electrical resistance of 24 diode leads was measured in the LHC machine during

Manuscript received July 16, 2013.

F. Savary is with CERN, Route de Meyrin 385, 1217 Meyrin, Switzerland (phone: +41 22 7662128, fax: +41 22 7676300, e-mail: Frederic.Savary@cern.ch)

M. Bajko, M. J. Bednarek, K. Dahlerup-Petersen, G. D'Angelo, G. Dib, C. Giloux, L. Grand-Clement, S. Izquierdo Bermudez, R. Moron-Ballester, H. Prin, V. Roger, A. Verweij, G. Willering, are with CERN. operation. Unexpectedly, high resistances of the order of $40 \mu \Omega$ were measured at a few locations (to be compared to expected $2 \mu \Omega$ and $5 \mu \Omega$ depending on the contact, see Table I), which triggered a comprehensive review of the diode behavior and of the associated current leads and bolted contacts. This paper describes the findings, and the remedies that will be implemented during the long shut down of the LHC machine to ensure safe operation [1].

\section{THE MAGNET PROTECTION SYSTEM AND THE DIODE STACKS}

\section{A. The magnet protection system}

The protection system comprises cold diodes, which are connected in parallel to each magnet in order to bypass the current in case of a quench in the magnet while ramping down the current in the entire circuit. At $10 \mathrm{kA}$, the resistance of the magnet is of the order of $600 \mu \Omega$ when the current starts flowing through the diode leads. The resistive voltage across the quenching magnet provokes a fast commutation of the current to its parallel diode. In this way, the quenched magnet is shorted on the diode, dumping its current in $\sim 0.5 \mathrm{~s}$, and the rest of the chain in superconductive state is slowly ramped down with time constants of the order of $100 \mathrm{~s}$. Both the diode and the diode leads should be capable of conducting an exponentially decaying current of $13 \mathrm{kA}$ with such time constants. In addition, quench heaters are embedded in the collared coils assembly. In case of a quench, the quench heaters are fired, and switch to the resistive state a sufficient volume of superconducting cable such that the stored energy can be safely dissipated in a larger volume of the coils, keeping maximum temperatures and voltages within safe limits [2].

\section{B. The diode stacks}

In order to avoid over-heating, the bypass diode is firmly compressed between two massive pieces of Electrolytic Tough Pitch Copper (Cu-ETP) acting as heat sink and high current lead. A compression force of $40 \mathrm{kN}$ is applied on the contact surfaces by means to three tie rods made of stainless steel and eight spring washers made of copper beryllium $\left(\mathrm{CuBe}_{2}\right)$. The dipole diode stack is composed of a bypass diode, two heat sinks, and two current leads (or bus bars) made of Oxygen Free Electronic Copper (Cu-OFE) for connection to the magnet and the electrical circuits. The quadrupole diode stack is composed of two bypass diodes, one per each aperture, four 
heat sinks, and eight current leads. There are three types of contacts in a diode stack assembly (see Fig. 1): (i) the halfmoon contacts in the dipole diode stacks, or connection plate contacts in the quadrupole diode stacks, (ii) the bus bar (BB) to heat sink (HS) contacts, and (iii) the bypass diode to heat sink contacts. Except the diode to heat sink contacts, which are clamped, all the contacts are assembled by means of bolts and spring washers that compensate for the differential thermal contraction between the fasteners made of stainless steel and the copper parts, and thus ensure that sufficient contact pressure is maintained after cool down. The electrical resistance requirements for these contacts are summarized in Table 1. A dipole diode stack assembly and a bypass diode are shown in Fig. 1. The stack is $460 \mathrm{~mm}$ height, including leads and half-moons, and has a diameter of $160 \mathrm{~mm}$.
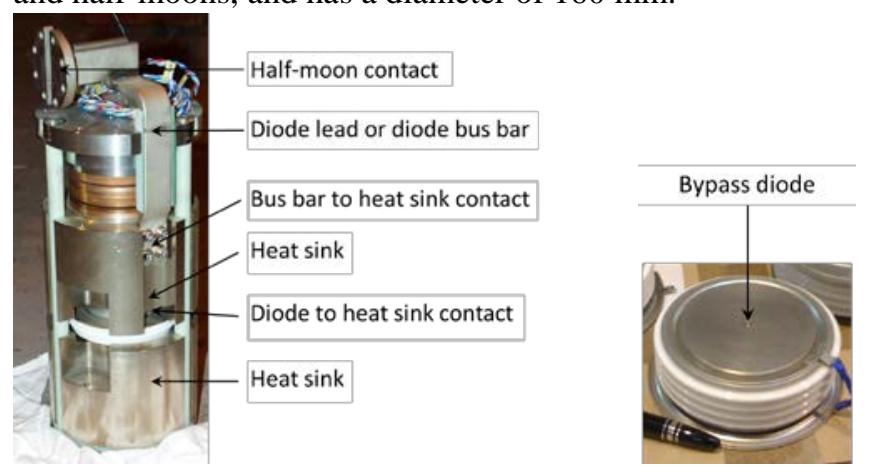

(a)

e stack assembly (a), and bypass dioc

(b)

TABLE I

ELECTRIC RESISTANCE REQUIREMENTS

\begin{tabular}{ll}
\hline \hline \multicolumn{1}{c}{ Contact } & Electrical resistance \\
\hline Half-moon and connection plate to bus bars & $2 \mu \Omega$ \\
Bus bar to heat sink & $2 \mu \Omega$ \\
Bypass diode to heat sink & $5 \mu \Omega$ \\
\hline \hline
\end{tabular}

\section{IN-SITU MEASUREMENTS}

The electrical resistance of 24 diode leads was measured in the LHC machine in the first half of 2011. During this measurements campaign, unexpectedly high resistances of the order of $40 \mu \Omega$ were measured. These findings triggered a comprehensive review of the design and working conditions of the diode stacks. Fig. 2 shows an example of measurements results for the quadrupole circuits. A sudden jump of resistance was observed during provoked quenches at $5 \mathrm{kA}$. This jump was peculiar, permanent, and could not be explained a priori.

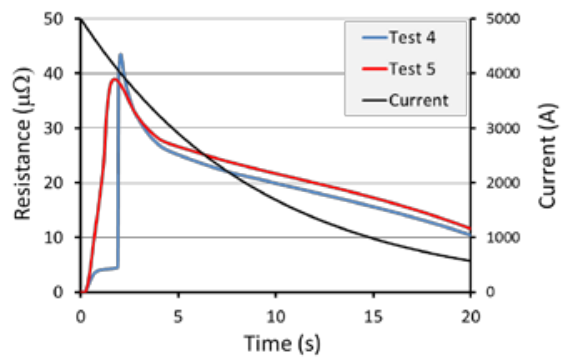

Fig. 2. In-situ Measurements of the electrical resistance of quadrupole circuits during provoked quenches at $5 \mathrm{kA}$.

\section{THERMAL AND MECHANICAL ANALYSIS}

\section{A. Thermal analysis}

The temperature of the diode wafer following a quench shall not exceed $300 \mathrm{~K}$, and that of the heat sink shall be limited to $230 \mathrm{~K}$. To verify whether these requirements can be achieved, temperature and electrical resistance measurements were carried out at $4.2 \mathrm{~K}$ on a specific test set-up, with diode stacks put in place in a container, as in the operational set-up. The impact of higher contact resistances on the temperature of the bypass diode and on the different contacts was analyzed.

Measurements carried out at $4.2 \mathrm{~K}$ and during a series of ten current decays at $13 \mathrm{kA}$ have shown that, even with a relatively high contact resistance of $30 \mu \Omega$ between the heat sink and the bypass diode, the heat sink temperature does not exceed the specified limit of $230 \mathrm{~K}$, see Fig. 3.

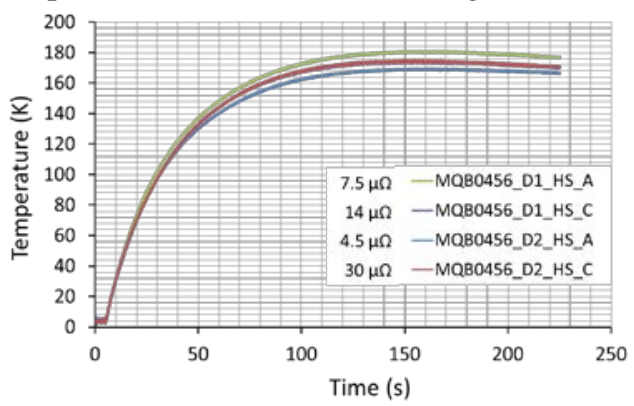

Fig. 3. Heat sink temperature vs time in a quadrupole diode stack assembly for different diode to heat sink contact resistances.

Regarding the bus bar to heat sink contact, it was shown that a resistance of $10 \mu \Omega$ would not jeopardize the bypass diode, as the dissipated energy would be intercepted entirely by the heat sink.

For the connection plate contacts of the quadrupole diodes, the above reasoning does not apply because of the very small amount of copper around these contacts. Temperature measurements were performed in order to study the heat propagation. Fig. 4 shows a typical set of temperature profiles corresponding to conforming connection plate contacts having a resistance of $2 \mu \Omega$.

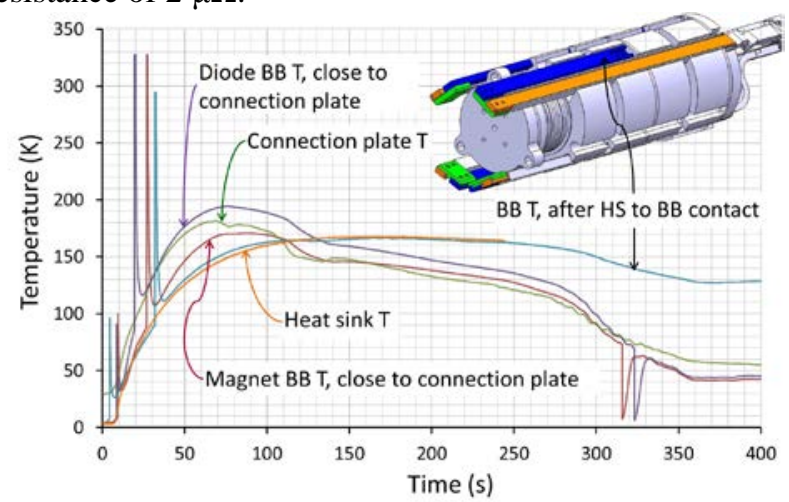

Fig. 4. Temperature evolution of conforming connection plate contacts with a resistance of $2 \mu \Omega$. The temperature peaks correspond to a change of sensor range.

For slightly excessive contact resistance, of the order of $3 \mu \Omega$, the heat propagation is different as illustrated in Fig. 5 . The maximum temperature in this case is exceeding $300 \mathrm{~K}$ 
nearby the connection plate, well above $200 \mathrm{~K}$ measured when the contact resistances are limited to $2 \mu \Omega$. This shows that a small excess resistance can have a significant impact on the temperature at the vicinity of the contact. However, it does not affect the heat sink temperature. Hence, the bypass diode remains safe.

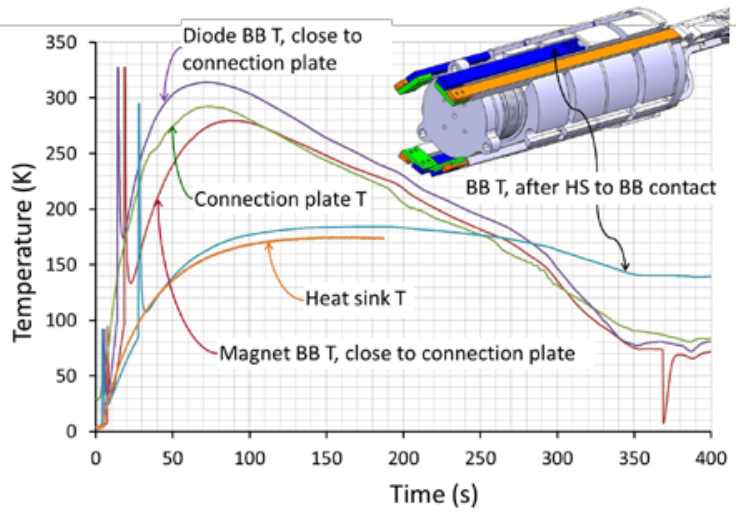

Fig. 5. Temperature evolution of non-conforming connection plate contacts with a resistance of $3 \mu \Omega$.

\section{B. Electro-mechanical analysis}

An electro-mechanical analysis was carried out to understand the available margins of the current design, with emphasis on the global compression force, and on the different bolted contacts. The fasteners used, and the assembly conditions are described in a detailed manufacturing procedure [3] of which an excerpt is given here in Table II for the bolted contacts.

TABLE II

ASSEMBly Conditions OF THE DiOde STACKS

\begin{tabular}{|c|c|c|c|c|}
\hline Item & $\begin{array}{l}\text { Dipole } \\
1 / 2 \text { moon }\end{array}$ & $\begin{array}{c}\text { Dipole } \\
\text { BB to HS }\end{array}$ & $\begin{array}{l}\text { Quadrupole } \\
\text { Conn. plate }\end{array}$ & $\begin{array}{l}\text { Quadrupole } \\
\text { BB to HS }\end{array}$ \\
\hline Bolt & $\begin{array}{l}\text { M6x30 } \\
\left(\mathrm{A} 4^{\mathrm{a}} 70^{\mathrm{b}}\right)\end{array}$ & $\begin{array}{l}\text { M6x25 } \\
\left({ }^{\text {A } 2 ~} 70\right)\end{array}$ & $\begin{array}{l}\text { M5x20 } \\
\text { (A2 70) }\end{array}$ & $\begin{array}{l}\text { M5x20 } \\
\text { (A2 70) }\end{array}$ \\
\hline Washer & 4 & 4 & 3 & 3 \\
\hline Helicoil $^{\mathrm{C}}$ & M6x10 & M6x12 & M5x7.5 & M5x10 \\
\hline Torque & $10 \mathrm{Nm}$ & $10 \mathrm{Nm}$ & $8 \mathrm{Nm}$ & $8 \mathrm{Nm}$ \\
\hline Preload/bolt & $6.5 \mathrm{kN}$ & $6.5 \mathrm{kN}$ & $6.5 \mathrm{kN}$ & $6.5 \mathrm{kN}$ \\
\hline \# of bolts & 4 & 4 & 2 & 3 \\
\hline Contact $\mathrm{P}^{\mathrm{d}}$ & 15.6 & 23.7 & 22.6 & 26.8 \\
\hline
\end{tabular}

a. A2 means Stainless Steel grade AISI 304, and A4 means Stainless Steel grade AISI 316

b. 70 defines the class of mechanical properties, and means an Ultimate Tensile Strength (UTS) of $700 \mathrm{~N} / \mathrm{mm}^{2}$ and a yield limit $\left(\sigma_{0.2}\right)$ of $450 \mathrm{~N} / \mathrm{mm}^{2}$

c. Thread inserts "Helicoil" are embedded in the copper parts

d. P denotes pressure

The heat sink is made of Cu-ETP of which the yield limit is $70 \mathrm{~N} / \mathrm{mm}^{2}$, and the bus bars are made of Cu-OFE, of which the yield limit is $240 \mathrm{~N} / \mathrm{mm}^{2}$. The contact surfaces have a nickel coating of 2-3 $\mu \mathrm{m}$, except those of the bus bars part of the magnet assembly, which have a silver coating of 5-10 $\mu \mathrm{m}$. The contact surfaces are cleaned with Scotch-Brite ${ }^{\mathrm{TM}}$ (except the silver coated surfaces) and alcohol prior to assembly. Medium strength thread locker blue ${ }^{\circledR}$ from Loctite ${ }^{\circledR}$ is used to reduce friction during the assembly, and to ensure locking of the assembly at cold.

The standard VDI2230 recommends lower torque for the M5 bolts, of the order of $5.7 \mathrm{Nm}$ (instead of $8 \mathrm{Nm}$ ). As a matter of fact, the yield limit in the bolts would be exceeded in this case. Tightening tests, including repeated tightening cycles in different conditions, were carried out in laboratory in order to determine the relationship between the tightening torque and the corresponding pre-load. These tests have shown that it is essential to replace the fasteners when redoing the assembly in order to meet the required performance, and that a given tightening torque will develop a higher pre-load when Loctite $^{\circledR}$ is utilized. Fig. 6 shows the results of the tightening tests for the M6 bolts of the dipole diode stacks.

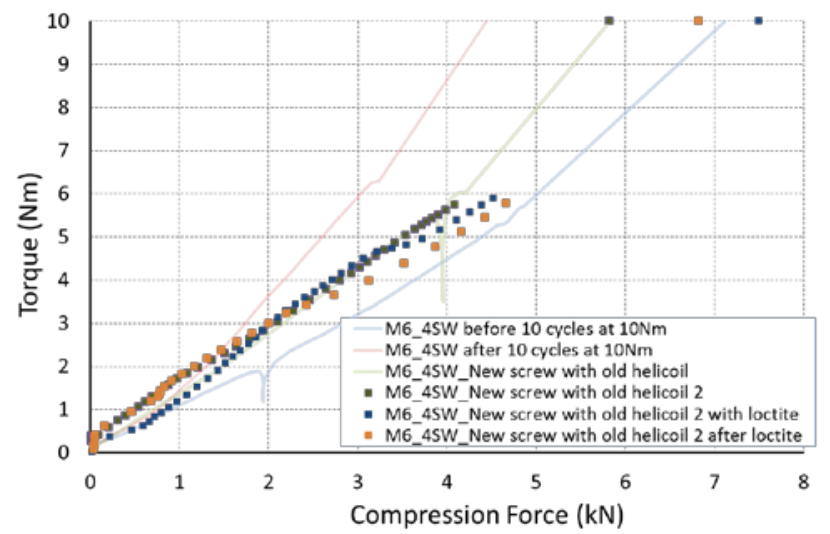

Fig. 6. Tightening tests with M6 bolts, before and after tightening cycles at $10 \mathrm{Nm}$, after replacement of the fasteners, and comparison with or w/o Loctite $^{\circledR}$.

Fig. 7 shows the dependence of the contact resistance with the tightening torque, and the preparation of the contact surfaces prior to assembly. The higher the tightening torque the lower the contact resistance. A thorough cleaning of the contact surfaces is essential to get lower contact resistance. Cleaning is always effective, even if the tightening torque is low. However, too low tightening torque would not be sufficient for the long-term integrity of the contact.

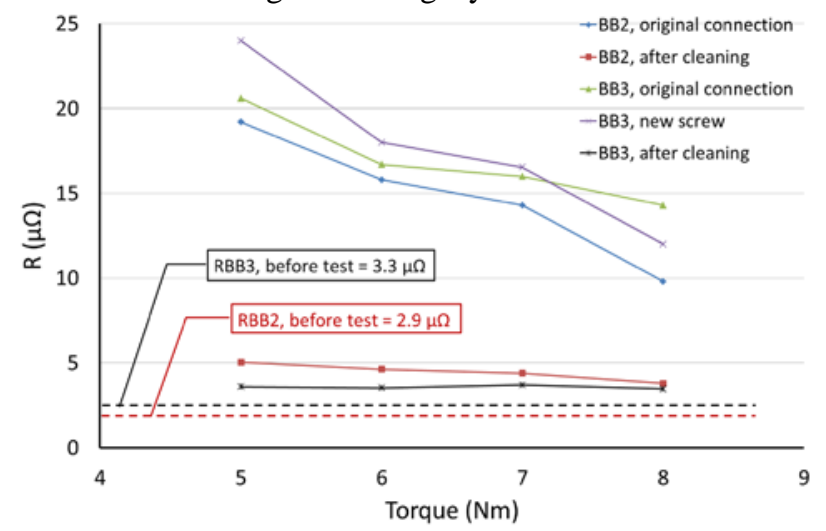

Fig. 7. Contact resistance as a function of the tightening torque, or contact pressure, for different surface preparations.

The electro-magnetic forces generated at $13 \mathrm{kA}$ between adjacent bus bars are repelling and, in the worst case, of the order of $700 \mathrm{~N}$, which is an order of magnitude less than the pre-load applied by each bolt. Therefore, these forces are deemed not to impact on the overall stability of the bolted assemblies. However, further tests carried out at $4.2 \mathrm{~K}$ and high current up to $13 \mathrm{kA}$ have shown that the bolted assemblies of the connection plate contacts of the quadrupole diode stacks are unstable at cold when subject to high current 
as from 5-6 kA, and after current cycling [4]. In some cases, the contact resistances can easily exceed the allowable limit of $2 \mu \Omega$, even if they were below the limit after assembly. In order to guarantee safe operation of the LHC machine for the next 20 years, it has been decided to redesign these bolted contacts, and to implement a consolidation plan as part of the long shut down of the LHC machine currently on-going at CERN.

\section{CONSOlidATED DESIGN}

\section{A. Description}

In order to improve the overall rigidity and stability of the bolted connection plates, the bolts are replaced by studs, which are screwed in a back-plate in order to avoid direct screwing in the former helicoils that are embedded in the rather soft $\mathrm{Cu}$ bus bars. A rectangular washer-plate made of stainless steel is used on the nut side in order to distribute better the tightening force on the connection plate. Two spring washers are used to compensate for the differential thermal contraction between the materials, and ensure that contact pressure is kept sufficient at cold conditions. The studs, nuts, washers, and the back-plate are made of Inconel 718 in order to allow higher pre-load at assembly and to increase the operation margin w.r.t. yield limit. A comparison of the key parameters between the original design shown in Fig. 8 (a) and the consolidated design shown in Fig. 8 (b) and (c) is given in Table III. The connection plates will be made of Cu-OFE (instead of Cu-ETP) in order to gain in RRR, and they will be silver coated in lieu of the original nickel coating, which shall contribute to decreasing the contact resistance. Furthermore, a silver oxide layer, in case of degradation of the contact surface, is prone to give lower contact resistance.

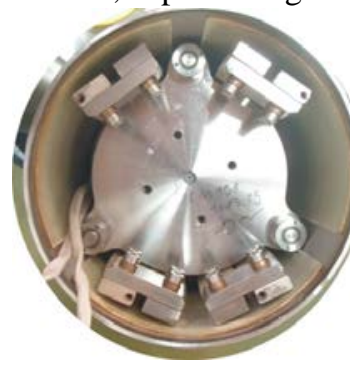

(a)

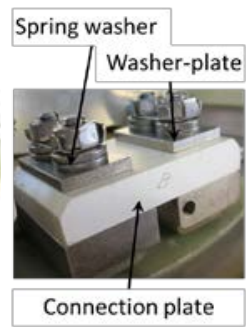

(b)

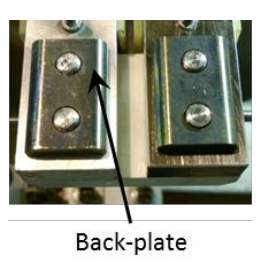

(c)
Fig. 8. End view of a quadrupole diode stack in its container with the original design of the bolted connection plates (a), consolidated design of the assembly seen from the nut side (b), and seen from the back-plate side (c).

TABLE III

Key Parameters Of The ORIginal AND Consolidated Designs

\begin{tabular}{lll}
\hline \hline \multicolumn{1}{c}{ Item } & \multicolumn{1}{c}{$\begin{array}{c}\text { Original } \\
\text { design }\end{array}$} & \multicolumn{1}{c}{$\begin{array}{c}\text { Consolidated } \\
\text { design }\end{array}$} \\
\hline Type/size & Bolt M5x20 & Stud M5x33 \\
Material & A2 70 & Inconel 718 \\
\# of bolts/studs & 2 & 2 \\
$\sigma_{0.2}$ & $450 \mathrm{~N} / \mathrm{mm}^{2}$ & $1200 \mathrm{~N} / \mathrm{mm}^{2}$ \\
UTS & $700 \mathrm{~N} / \mathrm{mm}^{2}$ & $1500 \mathrm{~N} / \mathrm{mm}^{2}$ \\
\# of washers & 3 & 2 \\
Torque & $8 \mathrm{Nm}$ & $12 \mathrm{Nm}$ \\
Preload/bolt & $6.5 \mathrm{kN}$ & $8 \mathrm{kN}$ \\
\hline \hline
\end{tabular}

\section{B. Validation tests}

Mechanical tests were carried out to demonstrate the validity and robustness of the consolidated design. Tightening tests on five representative assemblies, like shown in Fig. 8 (b) and (c), were executed till rupture using a torque wrench equipped with a torque sensor. The tightening torque before rupture is of the order of $20 \mathrm{Nm}$, well above the $12 \mathrm{Nm}$ quoted in Table III. The load developed in the stud, as a function of the applied torque, was also measured on five specimens, giving an average load to torque ratio of $0.74 \mathrm{kN} / \mathrm{Nm}$. Therefore, a torque of $10.8 \mathrm{Nm}$ is necessary to get the $8 \mathrm{kN}$ preload per bolt. In order to ensure the minimum required preload, taking into account inevitable variations throughout the consolidation activities, the nominal tightening torque was set to $12 \mathrm{Nm}$. A preload of $8 \mathrm{kN}$ corresponds to a stress of $560 \mathrm{~N} / \mathrm{mm}^{2}$, which is well below the yield limit of Inconel 718 as shown in Table III. The original bolts made of stainless steel grade A2 would not withstand it. Tensile tests were carried out on standard specimens to verify the mechanical strength of the material used for the studs. The tests confirmed the high values of $\sigma_{0.2}$ and UTS, $1331 \mathrm{~N} / \mathrm{mm}^{2}$ and $1540 \mathrm{~N} / \mathrm{mm}^{2}$, respectively. The elongation at break is $20 \%$ leaving sufficient elasticity. As for the original design, the utilization of thread locker and a careful cleaning of the contact surfaces prior to assembly are required.

The consolidated design was also tested on real quadrupole diode stack assemblies at $4.2 \mathrm{~K}$ and high current cycles up to $13 \mathrm{kA}$. The results of these tests, reported in [4], demonstrate the validity and robustness of the consolidated design.

\section{CONCLUSION}

The weak points of the original design of the protection diode stacks of the LHC main magnets have been identified thanks to a comprehensive test campaign complemented by thorough analyses. A solution to consolidate the connection plate contacts of the quadrupole diode stacks was developed, and validated by mechanical and electrical tests.

\section{ACKNOWLEDGMENT}

The authors wish to thank warmly $M$. Guinchard and $\mathrm{K}$. Velissaridis of the EN-MME group at CERN for the execution of the mechanical tests, S. Deleage and M. Favre of TE-MPE for the assembly of the diode stacks and the execution of the tests at RT / $77 \mathrm{~K}$, and finally R. Bouvier and F.A. Duprat of TE-MSC for the execution of the tests at $4.2 \mathrm{~K}$.

\section{REFERENCES}

[1] J.-Ph. Tock et al., "Consolidation Of The LHC Superconducting Circuits: A Major Step Towards $14 \mathrm{TeV}$ Collisions”, Proceedings of IPAC2012, New Orleans, Louisiana, USA, pp. 3575-3577.

[2] F. Rodriguez-Mateos et al., "The Protection System For The Superconducting Elements Of The Large Hadron Collider At Cern”, Proceedings of PAC1999, New York, USA, pp. 3200-3202.

[3] L. Grand-Clement, S. Izquierdo Bermudez, "Installation or substitution of the protection diode stack for the LHC SSS quadrupoles", CERN document EDMS 1217207, 2012.

[4] V. Roger et al., "Contact resistances in the cold bypass diode leads of the main LHC magnets”, Paper presented to this conference. 